\title{
Calibration and Operation of the PNL Barrel Assayer
}

R. J. Arthur

July 1991

Prepared for the U.S. Department of Energy under Contract DE-AC06-76RLO 1830

Pacific Northwest Laboratory Operated for the U.S. Department of Energy by Battelle Memorial Institute 


\title{
DISCLAIMER
}

This report was prepared as an account of work sponsored by an agency of the United States Government. Neither the United States Government nor any agency thereof, nor Battelle Memorial institute, nor any of their empioyees, makes any warranty, expressed or implied, or assumes any legal liability or responsibility for the accuracy, completeness, or usefulness of any information, apparatus, product, or process disclosed, or represents that its use would not infringe privately owned rights. Reference herein to any specific commercial product, process, or service by trade name, trademark, manufacturer, or otherwise does not necessarily constitute or imply its endorsement, recommendation, or favoring by the United States Government or any agency thereof, or Battelle Memorial Institute. The views and opinions of authors expressed herein do not necessarily state or reilect those of the United States Government or any agency thereof.

\author{
PACIFIC NORTHWEST LABORATORY \\ operated by \\ BATTELLE MEMORIAL INSTITUTE \\ for the \\ UNITED STATES DEPARTMENT OF ENERGY \\ under Contract DE-ACO6-76RLO 1830
}

Printed in the United States of America

Available to DOE and DOE contractors from the

Office of Scientific and Technical Information, P.O. Bux 62, Oak Ridge, TN 37831;

prices available from (615) 576-8401. FTS 626-8401.

Available to the public from the National Technical Information Service, U.S. Department of Commerce, 5285 Port Royat Rd., Springfield, VA 22161. 
PNL -7739

UC -506

\section{CALIBRATION ANO OPERATION}

OF THE PNL BARREL ASSAYER

R. J. Arthur

July 1991

Prepared for the U.S. Department of Energy under Contract DE-AC06-76RLO 1830

Pacific Northwest Laboratory Richland, Washington 99352 


\section{เ}




\section{$\underline{\text { SUMMARY }}$}

Pacific Northwest Laboratory operates a Barrel Assayer to measure the radionuclide content of 208-1iter waste drums. This mobile apparatus is designed to provide quantitative information on each radioisotope in a drum and to recognize and locate "hot spots" within the drum. A lead-collimated intrinsic-germanium detector mounted on a moveable platform vertically scans a rotating drum for gamma-ray activity while 62 stationary ${ }^{10} \mathrm{BF}_{3}$ tubes measure neutrons emitted by transuranic isotopes within the waste.

Several approaches have been used to document the controls under which the Barrel Assayer has been operated from February 1989 through December 1990. Resin-filled 208-l calibration barrels containing known quantities of ${ }^{60} \mathrm{Co}$, ${ }^{137} \mathrm{Cs}$, and ${ }^{134} \mathrm{Cs}$ were measured by the Barrel Assayer and found to be well within $25 \%$ of the known values. A thorium nitrate standard that served as the secondary, or field, standard verified that the detector has been within calibration during the period from February 1989 through December 1990.

In previous testing, 23 waste drums were assayed at several commercial nuclear power plants. Subsequently, aliquots from the top, middle, and bottom of the barrels were analyzed. The ratio of grab-sample concentration to direct-assay concentration averaged -1.6 for one plant and +1.3 for another.

Results using the Barrel Assayer were also comparable to those obtained using Safeguards \& Security's Segmented Gamma-ray Scanner (SGS) system in a cross-calibration experiment performed by a third party on several drums containing TRU wastes. 


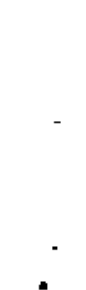




\section{CONTENTS}

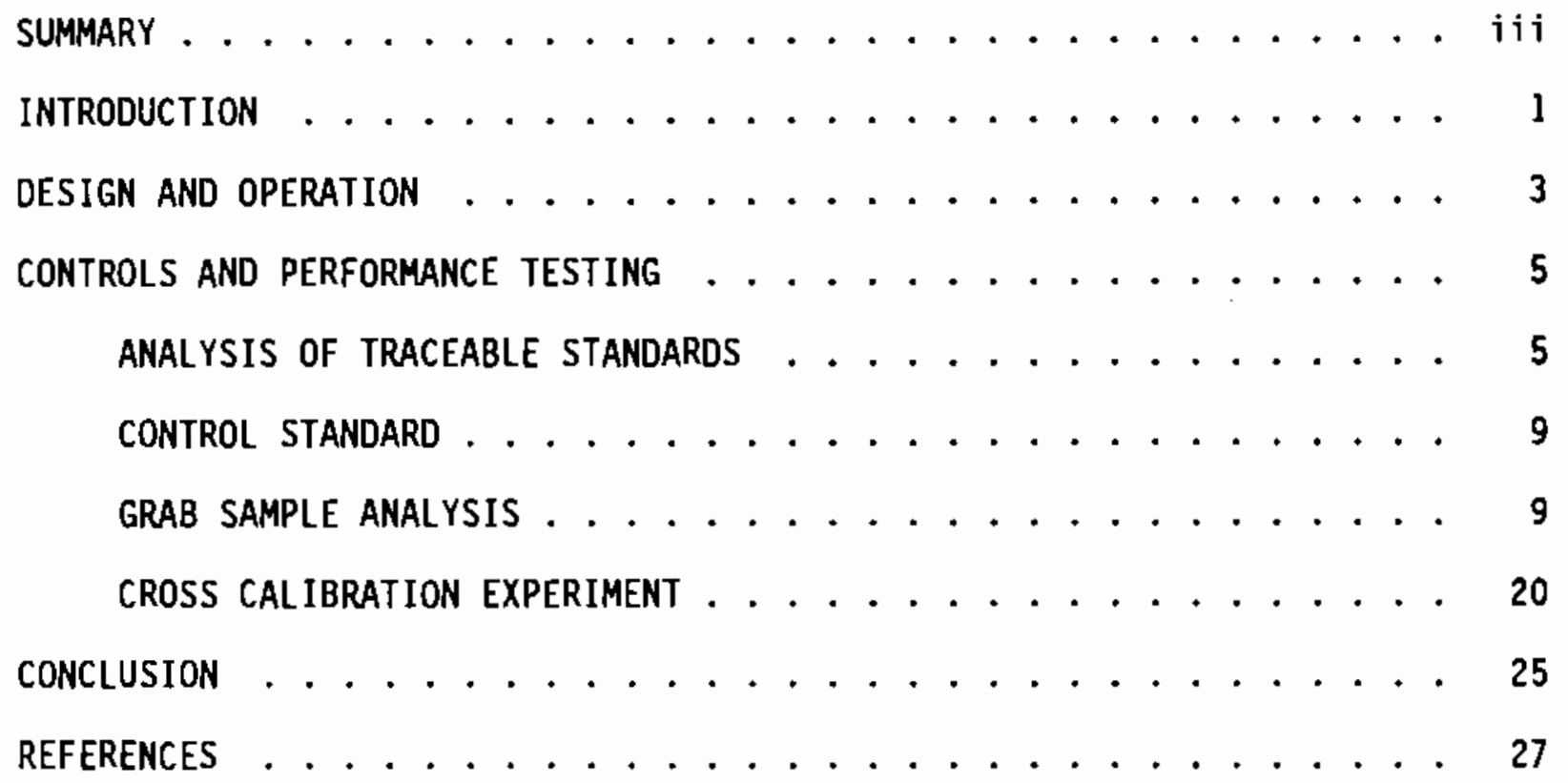




\section{FIGURES}

1 Schematic Diagram of 208-Liter Barrel Counter Used for Quantitative Isotopic Measurement of Gamma-Ray and Neutron Activity . . . . . .

2 Geometry of 208-Liter Drum Used For Calibration With a Mixed-Isotope Source as a Function of Source Geometry and Drum Weight . . . . .

3 208-Liter Drum Observed Efficiency Curves as a Function of Source Geometry and Drum Weight . . . . . . . . . . . . . . . 8

4 208-Liter Drum Calibration Curves (Observed and Extrapolated) Used to Generate Appropriate Efficiency Curve for Given Barrel Weight

5 Computer Output From CTL Program Demonstrating that the Detector Was Within Calibration (February 23, 1989 - July 23, 1990) . . . . 17

6 Computer Output From CTL Program Demonstrating that the Detector Was Within Calibration (February 2, 1990 - December 14, 1990) ...

\section{IABLES}

1 Results from Dow-Resin Filled Gamma-Ray Standard Drum Assay . . . . 6

2 Neutron Analysis Results From ${ }^{239}$ Pu Standard Canisters Centered in 55-Gallon Drum .................. . . . 10

3 Computer Results From CTL Program Used to Monitor Detector Reliability Based on Observed Peak Area and Resolution (February 23, 1989 - July 23, 1990) ................

4 Computer Results From CTL Program Used to Monitor Detector Reliability Based on Observed Peak Area and Resolution (February 2, 1990 - December 14, 1990)

5 Comparison of the Total Gamma-Ray Activity in 0il-Filled Drums by Grab Sampling Versus Direct Assay . . . . . . . . . . . . 19

6 Comparison of the Total Gamma-Ray Activity in Ion-ExchangeResin Filled Drums by Grab Sample Versus Direct Assay . . . . . . . 19

7 Comparison of Analytical Data on Critical-Mass-Laboratory Waste Drum .......................... 21

8 Material Balance Ratios . . . . . . . . . . . . . . . . 23

9 Ratio Comparison of Analytical Data on Critical-MassLaboratory Waste Drums 


\section{INTRODUCTION}

The Pacific Northwest Laboratory (PNL) ${ }^{(a)}$ operates the PNL Barrel Assayer, a mobile apparatus developed for measuring the radionuclide content of 208-1iter (55-gal) drums and similar smaller containers. Drums containing waste are positioned on a turntable, rotated, and directly measured using both a collimated IG gamma-ray spectrometer positioned at 11 equally-spaced intervals opposite the drum and 62 stationary ${ }^{10} \mathrm{BF}_{3}$ tubes embedded within two hemicycles of polyethylene moderator. Some of the advantages of this type of system are 1) the counting instrumentation can be transported to drum-storage locations, 2) very large sample sizes can be accommodated, 3) individual isotopic analysis and total gamma activity are determined, 4) the relative vertical distribution of activity within a drum may be determined from the scans, 5) sensitivity and counting geometry variability are improved by analyzing the sum of the 11 segmented gamma-ray scans, and 6) transuranic (TRU) levels can be determined.

This report briefly describes the operation of the Barrel Assayer and documents the controls under which it is and has been operated. The results of grab sample analyses and a cross-calibration experiment are also provided.

(a) Operated for the U.S. Department of Energy by Battelle Memorial Institute Under Contract DE-AC06-76RLO 1830. 



\section{DESIGN AND OPERATION}

The PNL Barrel Assayer is schematically illustrated in Figure 1. A leadcollimated, shielded intrinsic-germanium (IG) detector mounted on a movable platform vertically scans a drum from top to bottom. A magnetic position sensor accurate to $0.0025 \mathrm{~cm}$ is employed by the software controlling program, "SGS," to locate the detector platform within $0.25 \mathrm{~cm}$ of the specified height. A barrel is mounted on a turntable which rotates the drum at approximately 30 revolutions per minute during the vertical scanning. The vertical gammaray scanning is normally performed in eleven $7.6 \mathrm{~cm}$ segments for 208-1 drums, and the segment counts are summed to provide both total gamma-ray activity and specific activity, as well as individual isotopic activity. This information is useful in the event that some portion of the waste in the drum contains a highly unusual radionuclide composition.

The counting system contains a relatively large IG detector, typically with an efficiency for gamma-ray detection of between $19 \%$ and $30 \%$ (relative to a $7.6 \mathrm{~cm}$ by $7.6 \mathrm{~cm}$ right-circular sodium-iodide cylindrical detector). The detector is shielded on the side with $2.54 \mathrm{~cm}$ of lead. A $5-\mathrm{cm}$ lead collimator is used on the face of the diode with a slit of height $0.635 \mathrm{~cm}$ or $2.54 \mathrm{~cm}$, depending on the activity of the waste, exposing the full width of the diode.

The neutron detectors that surround the drum measure neutrons emitted by TRU isotopes within the waste. The detectors are embedded in polyethylene moderator to enhance the efficiency of the measurement. Additionally, TRU concentrations for $\mathrm{Pu}, \mathrm{Am}$, and $\mathrm{Cm}$ can be directly measured with the IG detector if their concentrations exceed about $1 \mathrm{nCi} / \mathrm{g}$ and if their gamma-ray emissions are not dominated by fission or activation product radiations.

Gamma-ray spectral data from the IG detector are collected and stored using a commercial (EG\&G ORTEC) ADCAM software program. The resulting 11 spectra from the analysis of a typical barrel are then summed together. The summed data are then reduced using the RAYGUN gamma-ray analysis program and experimentally determined efficiency curves.

The contents of a barrel are assumed to be packed homogeneously in the first analysis. For barrels with detectable activity, the analyst checks this 

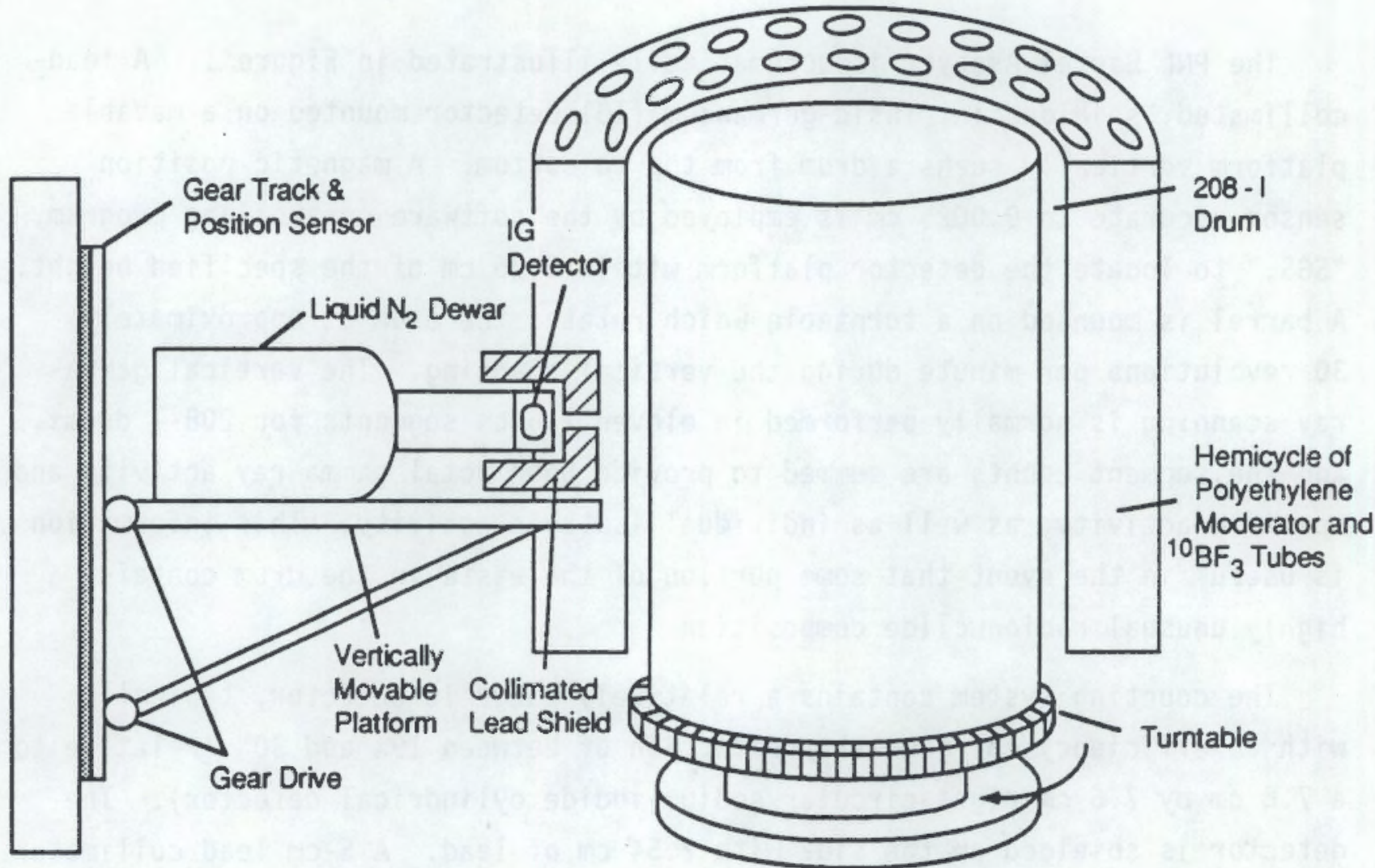

FIGURE 1. Schematic Diagram of 208-Liter Barrel Counter Used for Quantitative Isotopic Measurement of Gamma-Ray and Neutron Activity

assumption by observing the count rate for each segment and by looking at the resulting disintegration-per-second (dps) factors on radioisotopes with gammarays of several energies, such as ${ }^{239} \mathrm{Pu},{ }^{60} \mathrm{Co},{ }^{125} \mathrm{Sb},{ }^{134} \mathrm{Cs},{ }^{152} \mathrm{Eu}$, and ${ }^{154} \mathrm{Eu}$. If a discrepancy is noted in the dps factor, then several methods are available to correct the discrepancy. For example, the segments can be analyzed individually using an appropriate technique to approximate a more accurate attenuation correction.

Resulting gamma-ray spectra are deconvoluted using the RAYGUN gamma-ray analysis code (Hensley et al. 1988), which is based on the GAMANAL (Gunnink and Niday 1972) and GRPANL (Gunnink and Ruhter 1980) codes. Radioisotopes that are difficult to measure are determined on the basis of previously measured analog ratios (C1 ine and Noyce 1985). 


\section{CONTROLS AND PERFORMANCE TESTING}

Several approaches have been used to document the controls under which the Assayer has been operated from February 1989 through December 1990 . These include the analysis of traceable standards, use of a secondary or control standard tied to the traceable-standards analyses, analysis of waste barrels for a nuclear power plant in which quantitative radiochemical analyses were subsequently performed on grab samples from the barrels (Robertson et al. 1989), and a cross-calibration experiment performed by a third party using the Barrel Assayer and PNL Safeguards and Security's SGS scanning system.

\section{ANALYSIS OF TRACEABLE STANDARDS}

Two sets of calibration barrels were manufactured to 1) document the performance of the gamma-ray spectrometer, 2) establish efficiency curves, and 3) document the response when a "hot spot" or discrete radioactive particle is contained within the drum.

The first set of barrels was made by homogeneously mixing and solidifying Dow Resin with known quantities of ${ }^{60} \mathrm{Co},{ }^{137} \mathrm{Cs}$, and ${ }^{134} \mathrm{Cs}$. The cobalt was obtained from Amersham, and the two cesium radioisotopes were obtained from New England Nuclear Corp. as certified solutions in sealed glass ampules. The concentrated solutions were reconstituted to $25 \mathrm{ml}$ and the ampule was rinsed a minimum of 30 times with distilled water until all traces of radioisotope were removed from the glass ampule walls.

An aliquot of the reconstituted ${ }^{137}$ Cs solution was counted on a gamma-ray spectrometer that was calibrated against USGS and/or NIST standards. The computed activity agreed with the stated activity.

PNL technicians were specially trained by Dow in the procedures for solidifying Dow Resin, and the approved Dow procedure was followed for solidifying the Dow Resin.

Table 1 presents the gamma-ray activity levels expected for the resinfilled calibration barrel and the levels determined most recently by a re-analysis using the Barrel Assayer. All values are well within the $25 \%$ stated accuracy of the Barrel Assayer and are conservative concentrations. 
TABLE 1. Gamma-Ray Analysis Results from Dow-Resin Filled Gamma-Ray Standard Drum $(226.2 \mathrm{~kg})$ Assay

\begin{tabular}{|c|c|c|c|c|}
\hline ID Number & Isotope & $\begin{array}{c}\text { Expected } \\
\text { Activity (uCi) }\end{array}$ & $\begin{array}{c}\text { Observed } \\
\text { Activity (uCi) }\end{array}$ & \% Diff. \\
\hline $50037-29-1$ & ${ }^{137} \mathrm{Cs}$ & 2411 & 2704 & $+12 \%$ \\
\hline $50037-29-2$ & ${ }^{134} \mathrm{Cs}$ & 236.2 & 276.1 & $+17 \%$ \\
\hline $50037-29-4$ & ${ }^{60} \mathrm{Co}$ & 863.9 & 925.4 & $+7.1 \%$ \\
\hline
\end{tabular}

Figure 2 illustrates the second type of calibration barrel, one which was used to gauge the effects of various densities of waste material (i.e., matrix effects) on counting efficiencies. A certified mixed-radionuclide gamma-ray reference solution was obtained from Amersham and sealed in a $2 \mathrm{~cm}$ diameter $x$ $77 \mathrm{~cm}$ long thin-wall PVC tube. This standard was inserted into a series of PVC guide tubes placed inside an empty drum, as illustrated in Figure 2. The calibration tube was counted in each guide tube with the collimated IG detector as the drum rotated. Counts were performed for equal time intervals on equally-spaced segments along the length of the drum.

Efficiency curves were generated by filling the drum with materials of different density, as illustrated in Figure 3. Counts from each guide-tube position were then averaged to obtain the counting-efficiency curves for a "homogeneously" distributed source. Figure 4 shows the resulting countingefficiency curves for a homogeneous sample. A series of interpolated curves are shown to provide the necessary counting efficiency for any weight of drum up to $318 \mathrm{~kg}$.

A mixed-radionuclide calibration standard was used to simulate the presence of a "hot spot" or discrete radioactive particle in the drum. The source, serving essentially as a point, was counted at a number of positions inside the 208-1 drum and the response compared with the $77-\mathrm{cm}$ long standard for which the drum had been extensively calibrated. For relatively low sample densities, the point-source, mixed-radionuclide calibration standard produced counting-efficiency curves that were within $\pm 10 \%$ of those provided by the $77-\mathrm{cm}$ long standard. The approximate vertical locations of "hot spots" were 


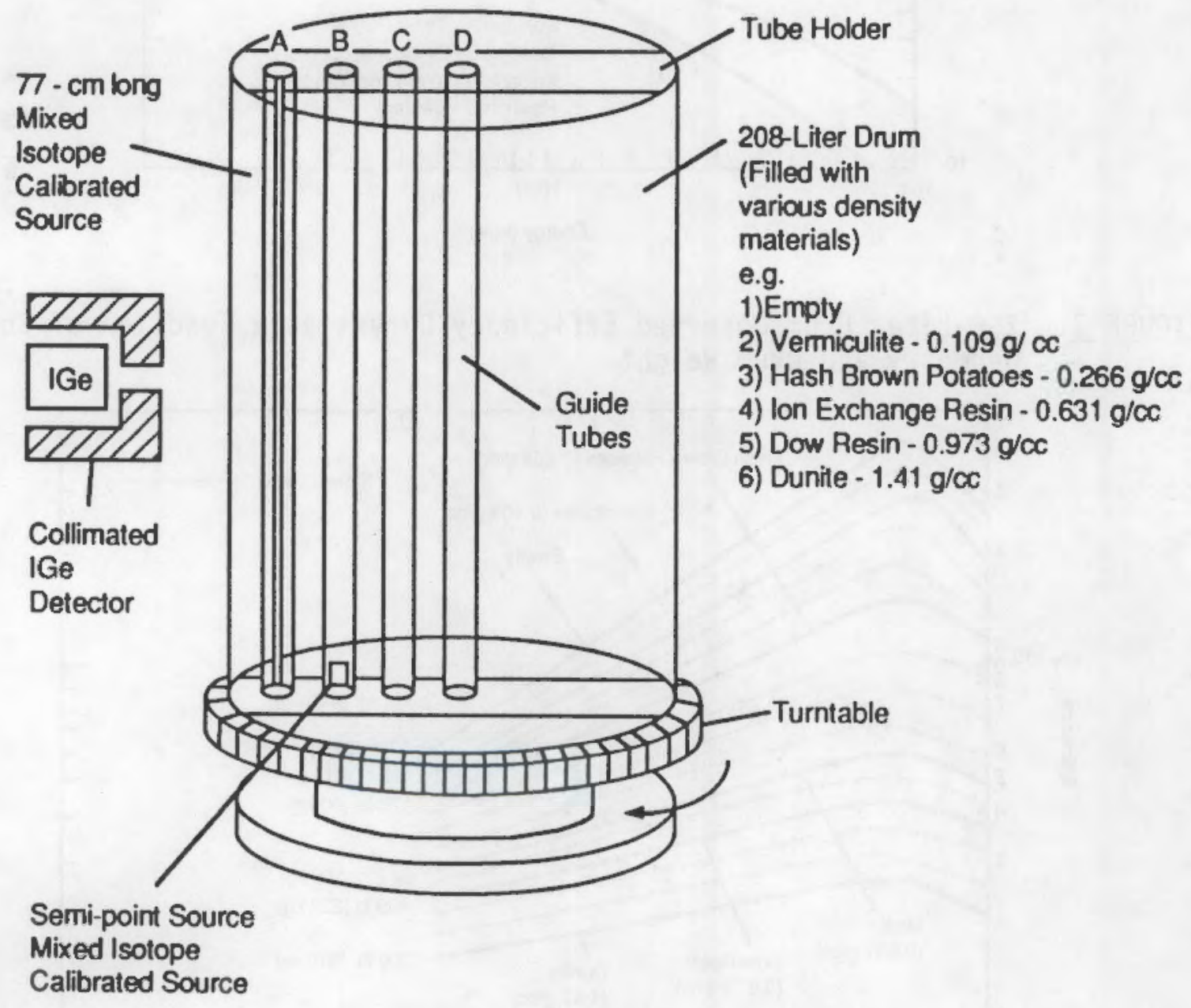

FIGURE 2. Geometry of 208-Liter Drum Used For Calibration With a MixedIsotope Sourceas a Function of Source Geometry and Drum Weight 


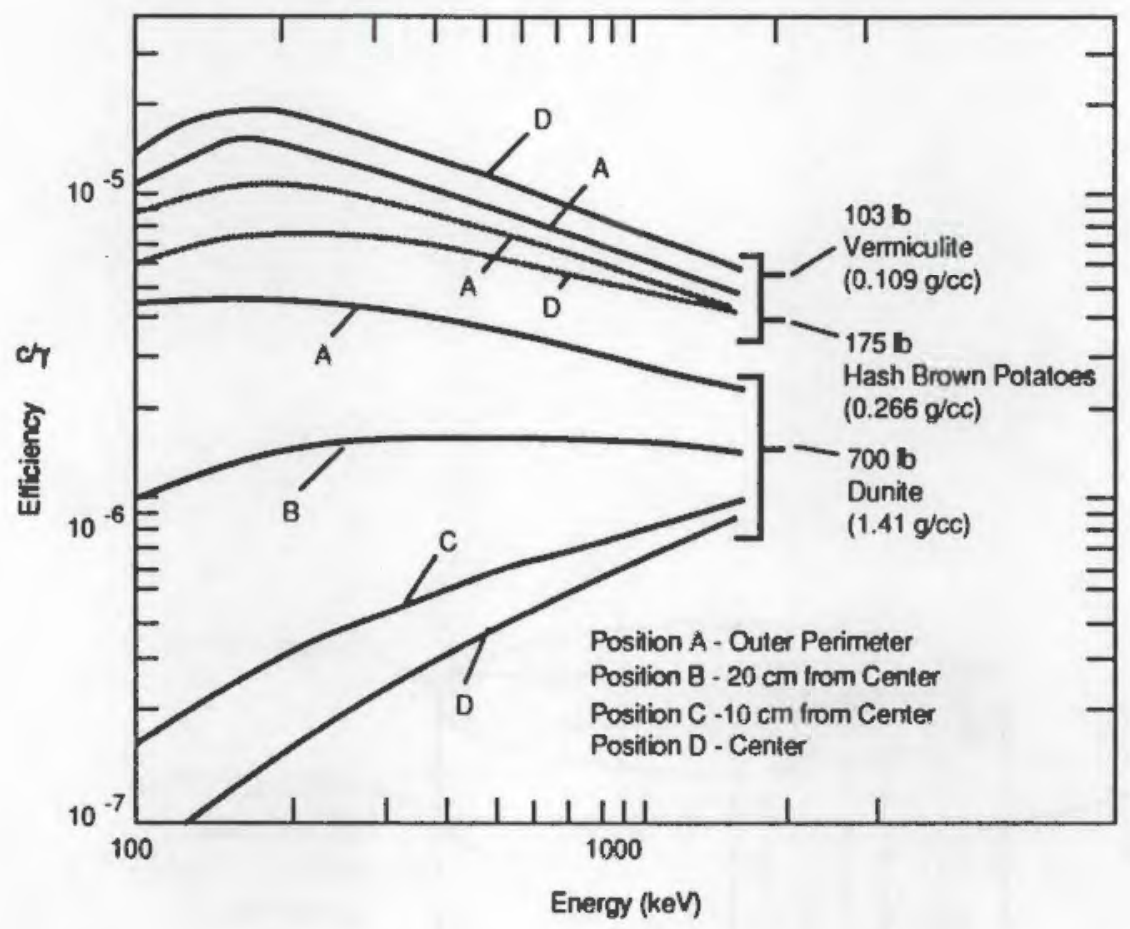

FIGURE 3. 208-Liter Drum Observed Efficiency Curves as a Function of Source Geometry and Drum Weight

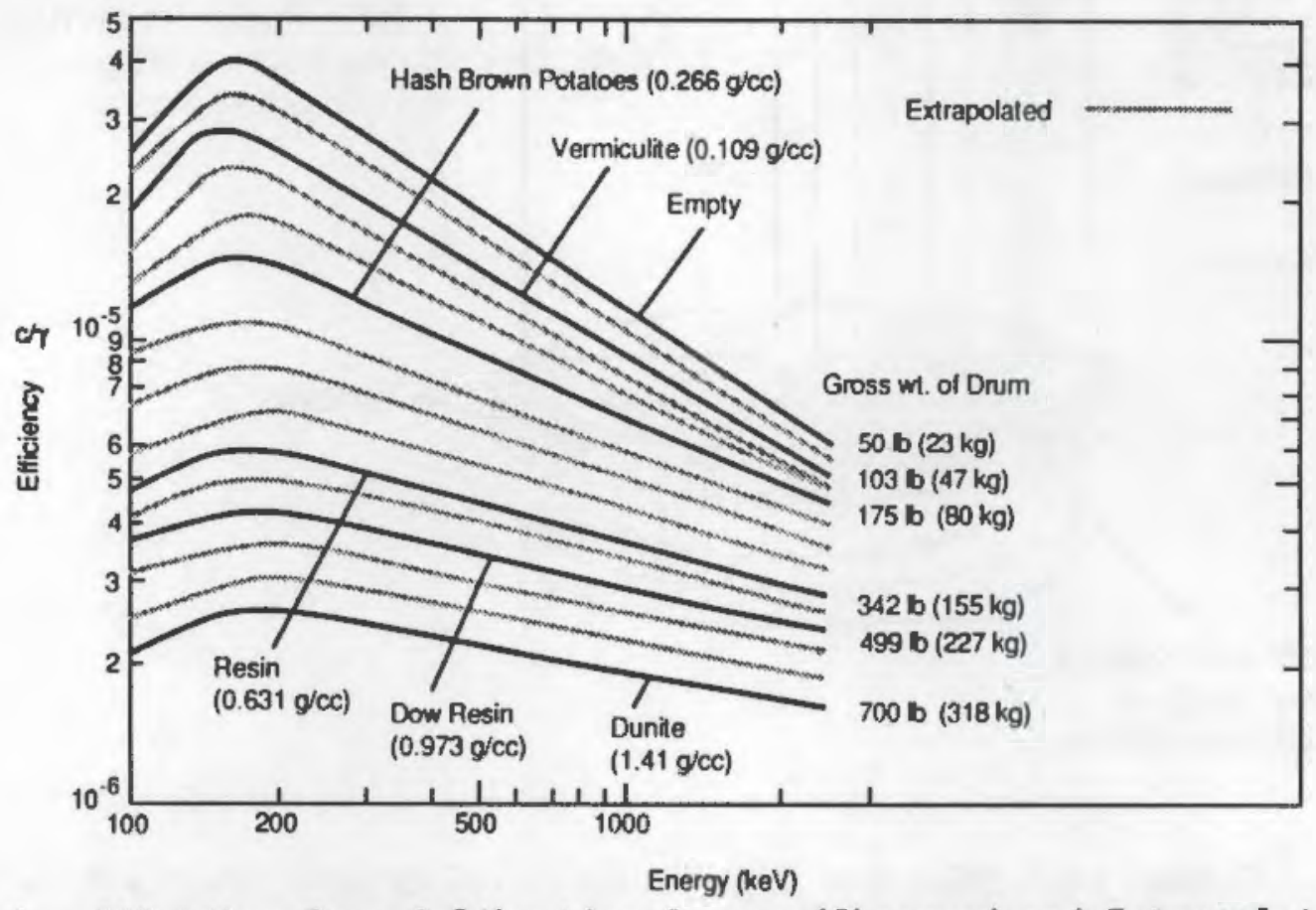

FIGURE 4. 208-Liter Drum Calibration Curves (Observed and Extrapolated) Used to Generate Appropriate Efficiency Curve for Given Barrel Weight 
identified within the drum by examining the spectra for individual segments along the drum.

To assess the reliability of the neutron detection system, several sets of standards were analyzed. For example, one set of standards is the NDA Safeguards Standards, consisting of two cans containing 7 Titers of Absorb-It thoroughly mixed with known quantities of $88.77 \%{ }^{239} \mathrm{Pu}$ nitrate stock solution, purified of ${ }^{241} \mathrm{Am}$ (analyzed by HEDL as sample \#Q7543). These standards are placed alone or together at various positions within an empty drum. Results of such analyses are presented in Table 2.

\section{CONTROL STANDARD}

A thorium nitrate standard (52733-38-1) was prepared and counted. This standard served as the secondary or control standard, with the resin-filled barrels serving as primary standards. Tables 3 and 4 and Figures 5 and 6 present values for the peak areas of selected thorium-standard ganma-rays obtained from the commercial ORTEC MCA software when applied to the control standard. The full-width at half-maximum (FWHM) values are merely for monitoring the energy-resolving characteristics of the IG detector and not for control purposes.

The control is typically run a second time if one of the values exceeds the $8 \%$ control limit. The system is out of control if the second run does not show the value to be in control. In the figures, a $4 \%$ limit is illustrated as a dotted line. The $8 \%$ limit is represented by the solid lines above and below the $4 \% 1$ imit lines.

\section{GRAB SAMPLE ANALYSIS}

Tables 5 and 6 contain values obtained by assaying 23 waste barrels at several commercial nuclear power plants. The barrels contained ion-exchange resins or oil. After being counted by the Barrel Assayer, aliquots were removed from the top, middle, and bottom of the barrels for radiochemical analysis.

Analysis of the segmented scans obtained from the Barrel Assayer used on oil-filled drums indicates that the activity is homogeneously distributed throughout the drum. The activity in the drum is likely to be present as 
TABLE 2. Neutron Analysis Results from ${ }^{239} \mathrm{Pu}$ Standard Canisters Centered in 55-Gallon Drum

\begin{tabular}{|c|c|c|c|c|c|}
\hline $\begin{array}{l}\text { ID Number \& } \\
\text { Position } \\
\text { Within Drum }\end{array}$ & $\begin{array}{c}\text { Net } \\
\text { Barrel } \\
\text { Weight (g) } \\
\end{array}$ & $\begin{array}{l}\text { Expected }{ }^{239} \mathrm{Pu} \\
\text { Weight }(\mathrm{g})\end{array}$ & $\begin{array}{r}\text { Obser } \\
\text { Weig } \\
\text { (Net }\end{array}$ & $\begin{array}{l}\text { ed }{ }^{239} \mathrm{Pu} \\
\mathrm{it}(\mathrm{g}) \\
\text { itron) }\end{array}$ & $\begin{array}{c}\text { Maximum }{ }^{239} \mathrm{Pu} \\
\text { Weight }(\mathrm{g}) \\
\text { (Neutron) }\end{array}$ \\
\hline $\begin{array}{l}\text { \#3 std } \\
\text { (Centered) }\end{array}$ & 14515 & 30.3 & $\begin{array}{r}30.5 \\
+/-4.2\end{array}$ & $(+0.7 \%)$ & $<37.1$ \\
\hline $\begin{array}{l}\# 4 \text { std } \\
\text { (Centered) }\end{array}$ & 16103 & 10.2 & $\begin{array}{r}10.3 \\
+/-1.5\end{array}$ & $(+1.0 \%)$ & $<12.6$ \\
\hline $\begin{array}{l}\# 3 \& \text { \&4 } \\
\text { (Centered) }\end{array}$ & 21773 & 40.5 & $\begin{array}{r}37.6 \\
+/-5.3\end{array}$ & $(-7.2 \%)$ & $<46.0$ \\
\hline $\begin{array}{l}\text { \#3 std } \\
\text { (Outer Middle) }\end{array}$ & 4082.4 & 30.3 & $\begin{array}{r}28.54 \\
+/-4.07\end{array}$ & $(-5.8 \%)$ & $<35$ \\
\hline $\begin{array}{l}\text { \#3 std } \\
\text { (Outer Bottom) }\end{array}$ & 4082.4 & 30.3 & $\begin{array}{r}27.26 \\
+/-3.88\end{array}$ & $(-10.0 \%)$ & $<35$ \\
\hline $\begin{array}{l}\# 3 \& \# 4 \\
\text { (Outer Middle) }\end{array}$ & 8618.4 & 40.5 & $\begin{array}{r}38.01 \\
+/-5.42\end{array}$ & $(-6.1 \%)$ & $<46.5$ \\
\hline
\end{tabular}

discrete particulates suspended in a uniform oil matrix, however, and a good deal of variability is expected in small grab samples. Even greater variability is expected in ion-exchange resin. It should also be noted that sampling only three regions in any one drum introduces significant error in the analysis.

The ratio of grab-sample concentration to direct-assay concentration presented in Table 5 shows acceptable agreement between the two measurement methods. 
TABLE 3. Computer Results From CTL Program Used to Monitor Detector Reliability Based on Observed Peak Area and Resolution (February 23, 1989 - July 23, 1990)

Decay Corrected $C / M$

\begin{tabular}{|c|c|c|c|c|c|c|}
\hline DATE & TH (238) & FWHM 238 & TH (911) & FWHM 911 & $\mathrm{TH}(2615)$ & FWHM2615 \\
\hline 23-FEB-89 & $6.3124 \mathrm{E}+04$ & 2.560 & $1.8721 \mathrm{E}+04$ & 2.840 & $1.0534 E+04$ & 3.900 \\
\hline 23-FEB-89 & $6.2568 \mathrm{E}+04$ & 2.580 & $1.8512 E+04$ & 2.860 & $1.0561 E+04$ & 3.870 \\
\hline 23-FE8-89 & $6.2552 E+04$ & 2.590 & $1.8632 E+04$ & 2.820 & $1.0532 \mathrm{E}+04$ & 3.710 \\
\hline 23-FE8-89 & $6.2297 E+04$ & 2.550 & $1.8710 E+04$ & 2.810 & $1.0399 E+04$ & 3.710 \\
\hline 23-FEB-89 & $6.3335 E+04$ & 2.560 & $1.8738 \mathrm{E}+04$ & 2.830 & $1.0583 \mathrm{E}+04$ & 3.690 \\
\hline 24-FEB-89 & $6.3280 E+04$ & 2.540 & $1.8258 \mathrm{E}+04$ & 2.810 & $1.0586 \mathrm{E}+04$ & 3.860 \\
\hline 24-FE8-89 & $6.2274 E+04$ & 2.530 & $1.8409 \mathrm{E}+04$ & 2.750 & $1.0574 E+04$ & 3.720 \\
\hline 24-FE8-89 & $6.2522 \mathrm{E}+04$ & 2.530 & $1.8547 E+04$ & 2.720 & $1.0555 \mathrm{E}+04$ & 3.870 \\
\hline 24-FEB-89 & $6.2891 \mathrm{E}+04$ & 2.370 & $1.8485 \mathrm{E}+04$ & 2.850 & $1.0554 \mathrm{E}+04$ & 3.720 \\
\hline 24-FEB-89 & $6.2285 \mathrm{E}+04$ & 2.550 & $1.8768 \mathrm{E}+04$ & 2.820 & $1.0553 E+04$ & 3.740 \\
\hline 15-MAR-89 & $6.2310 E+04$ & 2.260 & $1.8447 E+04$ & 2.510 & $1.0534 E+04$ & 3.520 \\
\hline 21-MAR-89 & $6.2714 E+04$ & 2.500 & $1.8964 E+04$ & 2.780 & $1.0491 E+04$ & 3.820 \\
\hline 28-MAR-89 & $6.2070 \mathrm{E}+04$ & 2.670 & $1.9221 \mathrm{E}+04$ & 2.960 & $1.0592 \mathrm{E}+04$ & 3.830 \\
\hline 28-MAR-89 & $6.2146 \mathrm{E}+04$ & 2.630 & $1.8461 E+04$ & 2.840 & $1.0556 \mathrm{E}+04$ & 3.890 \\
\hline $11-J U L-89$ & $6.2855 E+04$ & 3.260 & $1.8893 \mathrm{E}+04$ & 3.280 & $1.0280 \mathrm{E}+04$ & 4.170 \\
\hline $12-J U L-89$ & $6.3198 \mathrm{E}+04$ & 2.740 & $1.8838 \mathrm{E}+04$ & 2.880 & $1.0441 E+04$ & 3.880 \\
\hline $13-J U L-89$ & $6.3863 \mathrm{E}+04$ & 2.550 & $2.0326 \mathrm{E}+04$ & 2.870 & $1.0648 \mathrm{E}+04$ & 3.840 \\
\hline $17-J U L-89$ & $6.3386 E+04$ & 2.540 & $1.8473 \mathrm{E}+04$ & 2.790 & I. $0568 E+04$ & 3.910 \\
\hline $18-J U L-89$ & $6.3317 \mathrm{E}+04$ & 2.490 & $1.8653 \mathrm{E}+04$ & 1.810 & $1.0654 E+04$ & 3.680 \\
\hline 19-JUL-89 & $6.2214 E+04$ & 2.570 & $1.8505 E+04$ & 2.890 & $1.0514 E+04$ & 3.900 \\
\hline $31-J U L-89$ & $6.2668 \mathrm{E}+04$ & 2.160 & $1.8588 \mathrm{E}+04$ & 2.470 & $1.0789 E+04$ & 3.680 \\
\hline $17-A U G-89$ & $6.3826 E+04$ & 2.430 & $1.9861 E+04$ & 2.380 & $1.0668 \mathrm{E}+04$ & 3.960 \\
\hline
\end{tabular}


IABLE 3. (Cont inued)

Decay Corrected $C / M$

\begin{tabular}{|c|c|c|c|c|c|c|}
\hline DATE & $\mathrm{TH}(238)$ & FWHM 238 & TH (911) & FWHM 911 & $\mathrm{TH}(2615)$ & HM2615 \\
\hline 22-AUG-89 & $6.3034 E+04$ & 2.360 & $1.8753 E+04$ & 2.810 & $1.0431 E+04$ & 4.060 \\
\hline 22-SEP-89 & $6.2914 E+04$ & 2.590 & $1.8385 \mathrm{E}+04$ & 2.930 & $1.0638 E+04$ & 3.970 \\
\hline 25-SEP-89 & $6.0161 E+04$ & 3.240 & $1.8740 E+04$ & 3.310 & $1.0381 E+04$ & 4.180 \\
\hline 27-SEP-89 & $6.2598 E+04$ & 2.770 & $1.7816 \mathrm{E}+04$ & 3.010 & $1.0588 \mathrm{E}+04$ & 4.160 \\
\hline $2-0 C T-89$ & $6.1674 E+04$ & 2.430 & $1.7864 E+04$ & 2.730 & $1.0405 E+04$ & 3.750 \\
\hline $3-0 C T-89$ & $6.3549 E+04$ & 2.370 & $1.8767 \mathrm{E}+04$ & 2.720 & $1.0606 \mathrm{E}+04$ & 3.710 \\
\hline $19-0 C T-89$ & $6.2767 E+04$ & 2.210 & $1.9123 \mathrm{E}+04$ & 2.450 & $1.0788 \mathrm{E}+04$ & 3.630 \\
\hline $24-0 C T-89$ & $6.2999 \mathrm{E}+04$ & 2.150 & $N / A$ & $N / A$ & $1.0444 E+04$ & 3.480 \\
\hline $31-0 C T-89$ & $6.2917 E+04$ & 2.250 & $1.7859 E+04$ & 2.510 & $1.0563 E+04$ & 3.610 \\
\hline 2-NOV-89 & $6.2217 \mathrm{E}+04$ & 2.190 & $1.8735 E+04$ & 2.560 & $1.0632 E+04$ & 3.630 \\
\hline 8-NOV-89 & $6.4419 E+04$ & 2.430 & $1.8588 \mathrm{E}+04$ & 2.680 & $.0659 E+04$ & 3.650 \\
\hline 9-NOV-89 & $6.3120 E+04$ & 2.560 & $1.8986 E+04$ & 2.890 & $.0618 \mathrm{E}+04$ & 3.940 \\
\hline 27-DEC-89 & $6.4890 E+04$ & 2.190 & $N / A$ & N/A & $.0670 E+04$ & 3.810 \\
\hline 28-DEC-89 & $6.3566 \mathrm{E}+04$ & 2.180 & $1.9014 E+04$ & 2.360 & $.0738 E+04$ & 3.400 \\
\hline 5-JAN-89 & $6.4113 \mathrm{E}+04$ & 2.320 & $1.9141 \mathrm{E}+04$ & 2.620 & $1.0672 E+04$ & 3.610 \\
\hline $10-J A N-90$ & $6.3513 E+04$ & 2.280 & $1.8684 E+04$ & 2.600 & $1.0573 E+04$ & 3.630 \\
\hline 1 -FEB- 90 & $6.5527 E+04$ & 2.270 & $1.9380 E+04$ & 2.620 & $1.0745 E+04$ & 3.640 \\
\hline $11-A P R-90$ & $6.2430 E+04$ & 2.470 & $N / A$ & $N / A$ & $1.0543 E+04$ & 3.830 \\
\hline $20-A P R-90$ & $6.2790 E+04$ & 2.660 & $1.8543 E+04$ & 2.890 & $1.0158 E+04$ & 3.970 \\
\hline 1-MAY-90 & $6.3503 E+04$ & 2.550 & $1.8583 \mathrm{E}+04$ & 2.840 & $1.0660 \mathrm{E}+04$ & 3.840 \\
\hline $8-M A Y-90$ & $6.3100 E+04$ & 2.610 & $1.8304 \mathrm{E}+04$ & 2.920 & $1.0575 \mathrm{E}+04$ & 3.890 \\
\hline $11-M A Y-90$ & $6.3 \mathrm{E} 356+04$ & 2.380 & $1.8070 E+04$ & 2.760 & $1.0282 E+04$ & 3.800 \\
\hline 17-MAY-90 & $6.3107 E+04$ & 2.750 & $1.8162 \mathrm{E}+04$ & 2.920 & $1.0332 \mathrm{E}+04$ & 4.120 \\
\hline
\end{tabular}


IABLE 3. (Continued)

Decay Corrected $C / M$

\begin{tabular}{|c|c|c|c|c|c|c|}
\hline DATE & $\mathrm{TH}(238)$ & FWHM 238 & $\mathrm{TH}(911)$ & FWHM 911 & $\mathrm{TH}(2615)$ & FWHM2615 \\
\hline 25-MAY-90 & $6.2773 E+04$ & 2.450 & $1.8435 E+04$ & 2.740 & $1.0287 E+04$ & 3.920 \\
\hline $31-$ MAY -90 & $6.2542 E+04$ & 2.430 & $1.8836 \mathrm{E}+04$ & 2.020 & $1.0339 E+04$ & 3.680 \\
\hline $6-J U N-90$ & $6.4431 E+04$ & 2.540 & $1.8525 E+04$ & 2.810 & $1.0335 E+04$ & 3.920 \\
\hline 13-JUN-90 & $6.1172 E+04$ & 2.400 & $1.8775 E+04$ & 2.700 & $1.0602 E+04$ & 3.770 \\
\hline $19-3 \cup N-90$ & $6.3375 \mathrm{E}+04$ & 2.890 & $1.9133 E+04$ & 2.900 & $1.0529 E+04$ & 4.190 \\
\hline 34-JUN-90 & $6.2710 E+04$ & 2.990 & $1.8610 E+04$ & 3.090 & $1.0202 E+04$ & 4.080 \\
\hline 28-JUN-90 & $6.2607 E+04$ & 2.590 & $1.8790 E+04$ & 3.890 & $1.0204 E+04$ & 4.400 \\
\hline $5-J U L-90$ & $6.1831 E+04$ & 2.420 & I. $8832 E+04$ & 2.710 & $1.0052 E+04$ & 3.720 \\
\hline 9-JUL-90 & $6.2408 E+04$ & 2.780 & $1.8615 E+04$ & 2.840 & $1.0334 E+04$ & 3.750 \\
\hline $12-J U L-90$ & $6.4354 E+04$ & 3.040 & $1.8781 E+04$ & 3.170 & $1.0581 E+04$ & 4.090 \\
\hline $13-J U L-90$ & $6.3732 E+04$ & 2.720 & $1.6847 E+04$ & 2.000 & $1.0676 E+04$ & 3.980 \\
\hline $16-J U L-90$ & $6.2230 E+04$ & 2.710 & $1.8770 E+04$ & 2.860 & $1.0542 E+04$ & 3.070 \\
\hline $19-J U L-90$ & $6.3270 E+04$ & 3.020 & $1.9057 E+04$ & 3.150 & $1.0765 E+04$ & 4.020 \\
\hline $23-J U L-90$ & $6.2252 E+04$ & 2.620 & $1.9079 \mathrm{E}+04$ & 2.930 & $1.0670 E+04$ & 3.830 \\
\hline
\end{tabular}

Average

$6.2713 E+04$

2.536

$1.8578 \mathrm{E}+04$

2.811

$1.0570 E+04$

3.779 
IABLE 4. Computer Results From CTL Program Used to Monitor Detector Reliability 8ased on Observed Peak Area and Resolution (February 2, 1990 - December 14, 1990)

Decay Corrected $C / M$

\begin{tabular}{|c|c|c|c|c|c|c|}
\hline DATE & $\mathrm{TH}(238)$ & FWHM 238 & TH (911) & FWHM 911 & $\mathrm{TH}(2615)$ & WHM2615 \\
\hline 2-FE8-90 & $6.4560 \mathrm{E}+04$ & 2.250 & $1.8907 E+04$ & 2.420 & $1.0766 \mathrm{E}+04$ & 3.520 \\
\hline $5-F E B-90$ & $6.4456 \mathrm{E}+04$ & 2.330 & $1.9426 \mathrm{E}+04$ & 2.550 & $1.0563 E+04$ & 3.660 \\
\hline 29-MAR-90 & $6.2415 E+04$ & 2.170 & $N / A$ & $N / A$ & $1.0534 E+04$ & 3.430 \\
\hline 30-MAR-90 & $6.3097 \mathrm{E}+04$ & 2.230 & $1.8636 \mathrm{E}+04$ & 2.610 & $1.0641 E+04$ & 3.690 \\
\hline 5-APR-90 & $6.3464 E+04$ & 2.400 & $1.8641 \mathrm{E}+04$ & 2.630 & $1.0611 \mathrm{E}+04$ & 3.840 \\
\hline 9-APR-90 & $6.2923 E+04$ & 2.640 & $1.8495 \mathrm{E}+04$ & 2.730 & $1.0505 \mathrm{E}+04$ & 3.760 \\
\hline $11-A P R-90$ & $6.2438 \mathrm{E}+04$ & 2.470 & N/A & N/A & $1.0543 E+04$ & 3.830 \\
\hline 20-APR-90 & $6.2790 E+04$ & 2.660 & $1.8543 E+04$ & 2.890 & $1.0158 \mathrm{E}+04$ & 3.970 \\
\hline $1-M A Y-98$ & $6.3503 E+04$ & 2.550 & $1.8503 E+04$ & 2.840 & $1.0660 E+04$ & 3.840 \\
\hline 8-MAY-98 & $6.3180 E+04$ & 2.618 & $1.8304 \mathrm{E}+04$ & 2.928 & $1.0575 \mathrm{E}+04$ & 3.850 \\
\hline $11-$ MAY-90 & $6.3835 E+04$ & 2.380 & $1.8070 E+04$ & 2.760 & $1.0282 E+04$ & 3.800 \\
\hline 17-MAY-98 & $6.2107 E+04$ & 2.750 & $1.8162 \mathrm{E}+04$ & 2.920 & $1.0332 E+04$ & 4.120 \\
\hline 25 -MAY-90 & $6.2779 \mathrm{E}+04$ & 2.450 & $1.8435 E+04$ & 2.770 & $1.0397 \mathrm{E}+04$ & 3.930 \\
\hline $31-M A Y-90$ & $6.2542 E+04$ & 2.430 & $1.8836 \mathrm{E}+04$ & 2.800 & $1.0589 \mathrm{E}+04$ & 3.680 \\
\hline $6-J U N-90$ & $6.4451 E+04$ & 2.540 & $1.8525 \mathrm{E}+04$ & 2.810 & $1.0555 E+04$ & 3.920 \\
\hline $13-J U N-90$ & $6.1172 E+04$ & 2.408 & $1.8775 E+04$ & 2.780 & $1.0602 \mathrm{E}+04$ & 3.770 \\
\hline 19-JUN-98 & $6.3375 E+04$ & 2.890 & $1.9133 \mathrm{E}+04$ & 2.900 & $1.0529 E+04$ & 4.190 \\
\hline 24-JUN-90 & $6.2710 E+04$ & 2.990 & $1.8618 \mathrm{E}+04$ & 3.090 & $1.0502 E+04$ & 4.080 \\
\hline 28-JUN-90 & $6.2607 \mathrm{E}+04$ & 2.590 & $1.8750 E+04$ & 3.090 & $1.0284 E+04$ & 4.400 \\
\hline $5-J U L-90$ & $6.1031 E+04$ & 2.420 & $1.8832 \mathrm{E}+04$ & 2.710 & $1.0607 \mathrm{E}+04$ & 3.720 \\
\hline $9-J U L-90$ & $6.2408 E+04$ & 2.700 & $1.8615 E+04$ & 2.840 & $1.0334 E+04$ & 3.750 \\
\hline $12-J U L-90$ & $6.4354 E+04$ & 3.040 & $1.8701 E+04$ & 3.170 & $1.0581 E+04$ & 4.090 \\
\hline
\end{tabular}


IABLE 4. (Cont inued)

Decay Corrected $C / M$

\begin{tabular}{|c|c|c|c|c|c|c|}
\hline DATE & $\mathrm{TH}(238)$ & FWHM 238 & $\mathrm{TH}(911)$ & FWHM 911 & $\mathrm{TH}(2615)$ & FWHM2615 \\
\hline 13-JUL-90 & $6.3732 E+04$ & 2.720 & $1.8847 E+04$ & 2.880 & $1.0676 \mathrm{E}+04$ & 3.900 \\
\hline $16-J U L-90$ & $6.2238 E+04$ & 2.710 & $1.8770 E+04$ & 2.850 & $1.0542 \mathrm{E}+04$ & 3.640 \\
\hline $19-J U L-90$ & $6.3270 E+04$ & 3.020 & $1.9027 \mathrm{E}+04$ & 3.150 & $1.0765 \mathrm{E}+04$ & 4.090 \\
\hline $23-J U L-90$ & $6.2252 E+04$ & 2.620 & $1.9079 \mathrm{E}+04$ & 2.930 & $1.0649 E+04$ & 3.830 \\
\hline $27-J U L-90$ & $6.3129 E+04$ & 2.420 & $1.8773 E+04$ & 2.770 & $1.0801 E+04$ & 3.560 \\
\hline 2-AUG-90 & $6.4262 E+04$ & 2.490 & $1.8777 E+04$ & 2.740 & $1.0545 E+04$ & 3.720 \\
\hline 27-AUG-90 & $6.2479 E+04$ & 3.070 & $1.8576 \mathrm{E}+04$ & 3.280 & $1.0582 \mathrm{E}+04$ & 4.450 \\
\hline $30-A U G-90$ & $5.9445 E+04$ & 2.700 & $1.8619 E+04$ & 2.930 & $1.0573 E+04$ & 3.960 \\
\hline 31-AUG-90 & $6.3334 E+04$ & 2.850 & $1.8791 E+04$ & 2.920 & $1.0690 \mathrm{E}+04$ & 3.860 \\
\hline 4-SEP- 90 & $6.2736 E+04$ & 3.040 & $1.9153 E+04$ & 3.190 & $1.0558 \mathrm{E}+04$ & 3.980 \\
\hline 5-SEP-90 & $6.1939 E+04$ & 3.020 & $1.8759 E+04$ & 3.110 & $1.0574 E+04$ & 4.060 \\
\hline 12 -SEP-90 & $6.3417 E+04$ & 2.760 & $1.8844 E+04$ & 3.080 & $1.0518 \mathrm{E}+04$ & 3.940 \\
\hline 19-SEP-90 & $6.3757 E+04$ & 2.770 & $1.8565 E+04$ & 2.890 & $1.0515 E+04$ & 3.860 \\
\hline 21-SEP-90 & $6.2303 E+04$ & 2.640 & $1.8979 E+04$ & 2.970 & $1.0652 E+04$ & 3.910 \\
\hline 25-SEP-90 & $6.3170 E+04$ & 3.030 & $1.7862 E+04$ & 3.170 & $1.0613 E+04$ & 4.100 \\
\hline 26-SEP-90 & $6.2179 E+04$ & 2.960 & $1.9021 E+04$ & 3.860 & $1.0802 E+04$ & 3.940 \\
\hline 27-SEP-90 & $6.4044 E+04$ & 2.940 & $1.9293 \mathrm{E}+04$ & 3.120 & $1.0702 E+04$ & 3.930 \\
\hline $3-0 C T-90$ & $6.3554 E+04$ & 2.820 & $1.9161 E+04$ & 2.880 & $1.0726 \mathrm{E}+04$ & 3.840 \\
\hline $4-0 C \mathrm{CT}-90$ & $6.3386 \mathrm{E}+04$ & 2.860 & $1.9030 \mathrm{E}+04$ & 2.940 & $1.0669 \mathrm{E}+04$ & 3.890 \\
\hline $17-0 \mathrm{CT}-90$ & $6.2903 E+04$ & 2.200 & $1.8402 E+04$ & 2.550 & $1.0754 E+04$ & 3.500 \\
\hline $9-0 C T-90$ & $6.1816 E+04$ & 2.860 & $1.8540 E+04$ & 3.010 & $1.0728 \mathrm{E}+04$ & 3.980 \\
\hline
\end{tabular}


IABLE 4. (Continued)

Decay Corrected C/M

\begin{tabular}{|c|c|c|c|c|c|c|}
\hline DATE & TH (238) & FWHM 238 & $\mathrm{TH}(911)$ & FWHM 911 & $\mathrm{TH}(2615)$ & WHM2615 \\
\hline $14-\mathrm{DEC}-90$ & $6.0324 \mathrm{E}+0.4$ & 2.820 & $1.8796 \mathrm{E}+04$ & 2.980 & $1.0419 E+04$ & 3.810 \\
\hline 14-DEC-90 & $6.2074 E+04$ & 2.400 & $1.8496 \mathrm{E}+04$ & 2.720 & $1.0515 E+04$ & 3.620 \\
\hline Average & $6.2713 E+04$ & 2.536 & $1.8578 E+04$ & 2.811 & $1.054 E+04$ & 3.779 \\
\hline
\end{tabular}




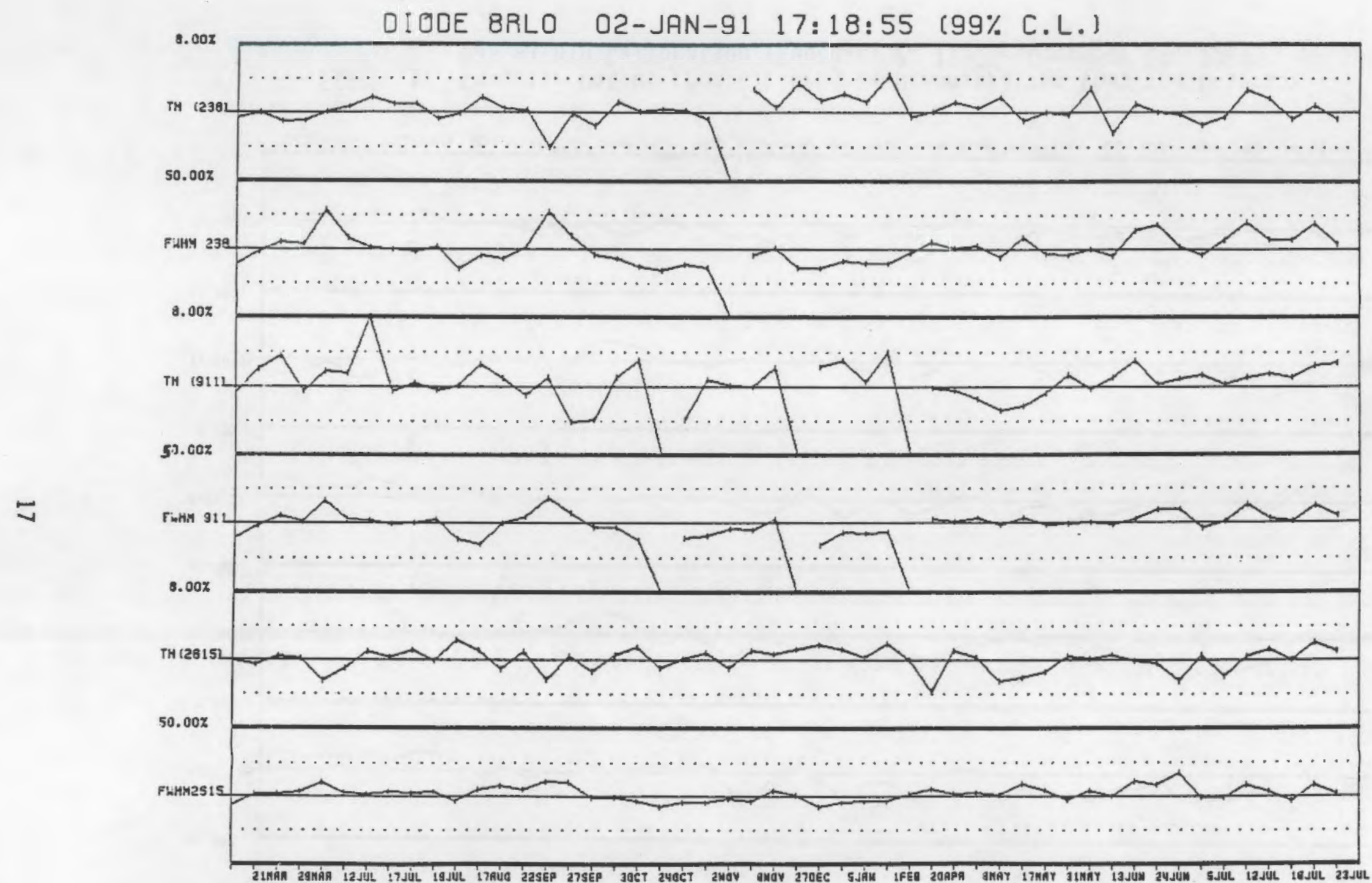

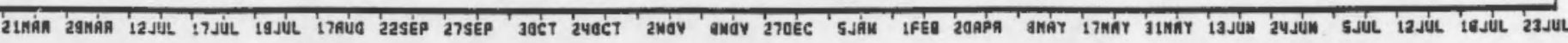

FIGURE 5. Computer Output from CTL Program Demonstrating that the Detector Was Within Calibration (February 23, 1989 - July 23, 1990) 


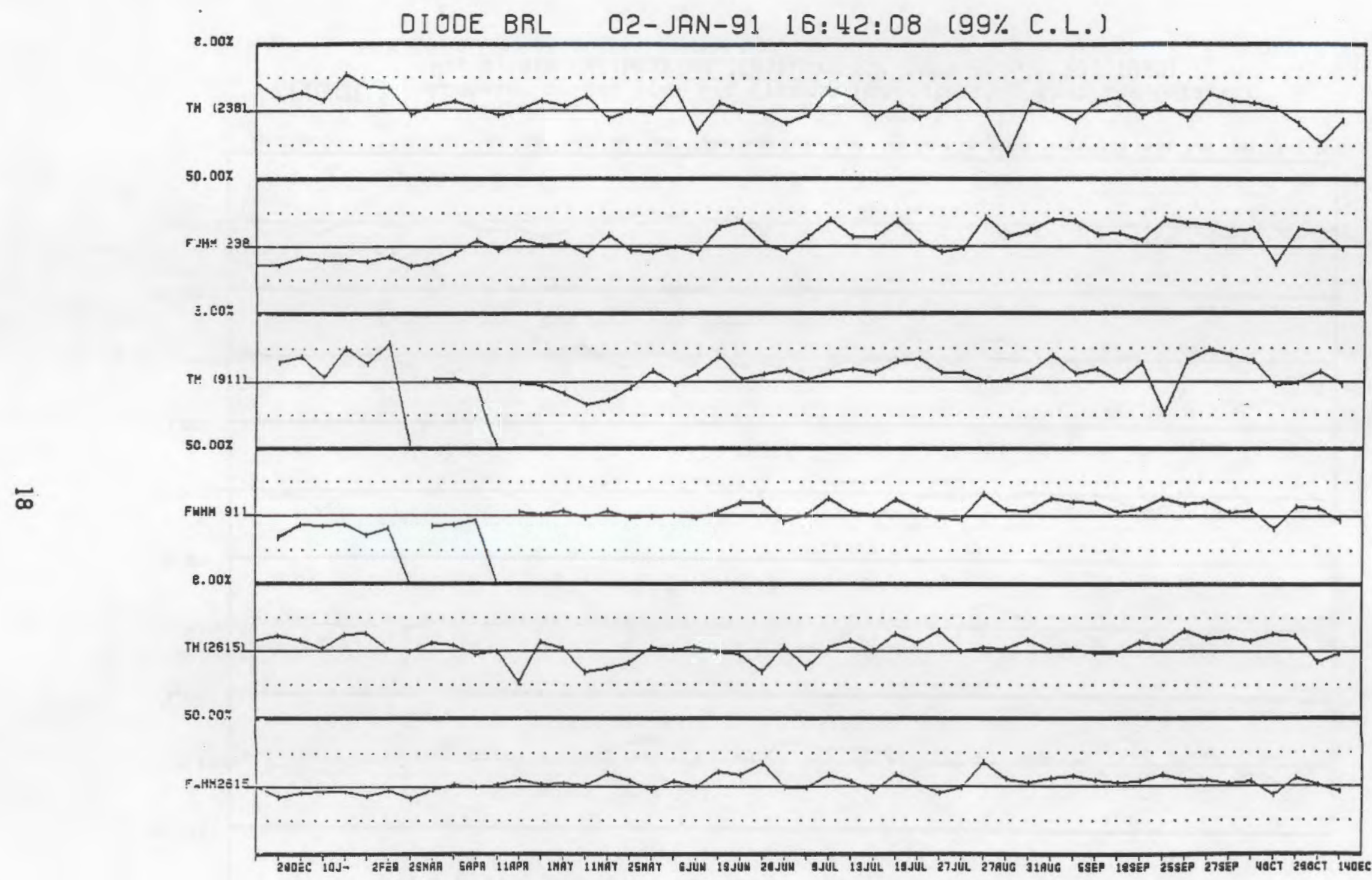

FIGURE 6. Computer Output from CTL Program Demonstrating that the Detector Was Within Calibration (February 2, 1990 - December 14, 1990) 
IABLE 5. Comparison of The Total Gamma-Ray Activity in 0i1Filled Drums By Grab Sampling Versus Direct Assay

\begin{tabular}{|c|c|c|c|c|}
\hline \multirow[b]{2}{*}{ Plant ID } & \multirow[b]{2}{*}{ Drum No. } & \multicolumn{3}{|c|}{ Concentration $(\mathrm{OCi} / \mathrm{q})$} \\
\hline & & $\begin{array}{l}\text { Range or Ave. of } \\
\text { Grab Sampling }\end{array}$ & Direct Assay & $\begin{array}{c}\text { Ratio of } \\
\text { Grab/Direct }\end{array}$ \\
\hline $\begin{array}{l}L \\
L \\
L \\
L \\
L\end{array}$ & $\begin{array}{l}10 \\
15 \\
29 \\
30 \\
31 \\
32\end{array}$ & $\begin{array}{l}(0.9-1.4) \\
(0.5-4.2) \\
(1.2-6.3) \\
(6.1-7.0) \\
(8.3-10.9) \\
(16-143)\end{array}$ & $\begin{array}{l}0.60 \\
0.28 \\
0.47 \\
17.0 \\
1.6 \\
20\end{array}$ & $\begin{array}{l}+1.8 \\
+6.8 \\
+7.4 \\
-2.7 \\
+6 \\
+2.6\end{array}$ \\
\hline $\begin{array}{l}L \\
L \\
L \\
L\end{array}$ & $\begin{array}{l}203 \\
235 \\
236 \\
237\end{array}$ & $\begin{array}{c}0.57 \\
40 \\
5.4 \\
5\end{array}$ & $\begin{array}{l}4.2 \\
73 \\
13 \\
74\end{array}$ & $\begin{array}{l}-7.4 \\
-1.8 \\
-2.4 \\
-15\end{array}$ \\
\hline Average for & int $\mathrm{L}$ & 12.4 & 20.4 & -1.6 \\
\hline
\end{tabular}

IABLE 6. Comparison of the Total Gamma-Ray Activity in Ion-Exchange-Res in Filled Drums By Grab Sampling Versus Direct Assay

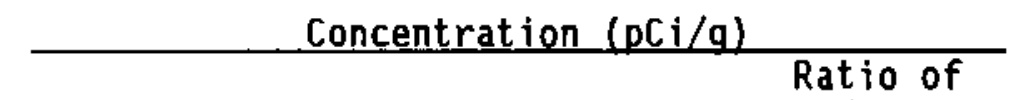

Plant ID Drum No. Grab Sampling Direct Assay Grab/Direct

\begin{tabular}{|c|c|c|c|c|}
\hline $\begin{array}{l}B \\
B \\
B \\
B \\
B \\
B \\
B \\
B \\
B \\
B \\
B \\
B \\
B\end{array}$ & $\begin{array}{l}R-58 \\
R-59 \\
R-60 \\
R-61 \\
R-62 \\
R-63 \\
R-64 \\
R-65 \\
R-66 \\
R-67 \\
R-68 \\
R-69 \\
R-70\end{array}$ & $\begin{array}{c}5.2 \\
36 \\
19 \\
2.1 \\
4.5 \\
4.9 \\
4.6 \\
0.81 \\
1.4 \\
1.5 \\
24 \\
0.68 \\
28 .\end{array}$ & $\begin{array}{c}9.2 \\
11 \\
5.1 \\
15 . \\
7.6 \\
8.5 \\
7.6 \\
7.2 \\
5.1 \\
3.9 \\
1.7 \\
3.6 \\
8.2\end{array}$ & $\begin{array}{r}-1.8 \\
+3.3 \\
+3.7 \\
-7.1 \\
-1.7 \\
-1.7 \\
-1.7 \\
-8.9 \\
-3.6 \\
-2.6 \\
+14.1 \\
-5.3 \\
+3.4\end{array}$ \\
\hline & $\mathrm{t} B$ & 10.2 & 7.76 & +1.3 \\
\hline
\end{tabular}




\section{CROSS-CALIBRATION EXPERIMENT}

In Table 7, results using Safeguards Security's SGS scanning system are compared with those using the PNL Barrel Assayer(a). Safeguards \& Security's SGS system uses segment-by-segment transmission corrected data to account for different matrix densities. Essentially all drums contained TRU wastes. Drums which were assayed without replication are listed first. The contents of some drums were rearranged and analyzed twice (such as Drum 2 and $2 A$, Drum 83 and $83 \mathrm{~A}$, Drum 85 and 88 , and Drum 86 and 89 ) which provides information on variability due to geometry. The contents of several of the drums were assayed as pieces in addition to being assayed as a whole; the various combinations are noted in Table 7 . These data provided information for a material balance comparison.

Several results were available from the PNL Barrel Assayer besides the "best" value, such as low, median, and high values as determined by the gammaray and the neutron analysis. A ratio was determined based on replicate analyses to gauge how well results from the analysis of a whole compared to the analyses of the parts. The results of the analysis are presented in Table 8. An additional more detailed breakdown is given in Table 9. Except for the singly measured drums $17 \mathrm{~A}$ and 91 , the agreement is generally excellent.

The results of the "low value determined by neutron analysis" under heading 4 of Table 8 agree the best with the results of the Safeguards and Security SGS scanning system and show the smallest standard deviation. Such an outcome is consistent with the highly penetrating nature of neutrons and the strong dependence on matrix of gamma-ray detection. These data also emphasize one of the strong features of the PNL Barrel Assayer design: for TRU waste the neutron analysis provides an excellent absolute measure of TRU content while the gamma-ray analysis provides an excellent measure of the relative ratios of the associated isotopes.

(a) H.H. Van Tuyl, "Update on CML Waste Drums." Memo to W.D. Richmond dated December 2, 1989, (Project Number HHV33/6). 
TABLE 7. Comparison of Analytical Data on Critical-Mass-Laboratory Waste Drums

\begin{tabular}{|c|c|c|c|c|}
\hline \multirow{2}{*}{$\underline{\text { Drum }}$} & \multirow{2}{*}{$\begin{array}{l}\text { Safeguards } \\
\frac{\text { \& Security }}{\text { Gamma }}(\mathrm{g} \mathrm{Pu})\end{array}$} & \multicolumn{3}{|c|}{ Barrel Assayer (g Pu) } \\
\hline & & Gamma & Neutron & \multirow{2}{*}{$\frac{\text { "Best" }}{36.4}$} \\
\hline 13 & 44.7 & $30.9-79.3$ & $34.2-36.4$ & \\
\hline $17 \mathrm{~A}$ & 204 & $>71.3$ & $52.2-256$ & 72 \\
\hline 20 & & 1.39 & 0.842 & 1.39 \\
\hline 21 & & & $<0.0034$ & $<0.0034$ \\
\hline 52 & 61.0 & $63.1-187$ & 57.5 & 63.1 \\
\hline 69 & $<0.002$ & & 0.00531 & 0.00531 \\
\hline 79 & 50.1 & $42.1-59.4$ & $47.1-47.3$ & 47.2 \\
\hline BO & 78.3 & $58.4-75 . B$ & $63.4-63.5$ & 63.5 \\
\hline 81 & 49.4 & $30.2-30.3$ & 25.2 & 30.2 \\
\hline 82 & 74.0 & $57.4-117$ & $33.6-35.8$ & 57.4 \\
\hline 90 & 2.6 & $>1.26$ & $<0.0086$ & 1.3 \\
\hline 91 & 3.6 & $>1.94$ & 0.527 & 1.9 \\
\hline 93 & 14.9 & $>14.3$ & $14.3-40.8$ & 15 \\
\hline \multicolumn{5}{|c|}{ Drum $2=$ Drum $2 A$} \\
\hline 2 & 34.2 & $35.9-111$ & $31.1-81.7$ & 36.8 \\
\hline $2 A$ & 28.0 & 48.6 & $31.7-76.8$ & 49 \\
\hline
\end{tabular}

Drum $67=$ Drums $86+83+2+85$

$\begin{array}{rcccccc}67 & 127.3 & 251 & -1790 & 252 & -254 & 254 \\ 86 & 34.2 & 42.9-90.3 & 37.9-107.7 & 42.9 \\ 83 & 65.2 & 48.8-125.8 & 44.7-127.0 & 68.8 \\ 2 & 34.2 & 35.9-111 & 31.1-81.7 & 36.8 \\ 85 & 273 & 229-993 & 267-709 & 267\end{array}$

Drum $70=$ Drums $70 A+62 A+83 B$

$\begin{array}{lcccc}70 & 185.8 & 27.9-943.4 & 93.0-123 & 106 \\ 70 \mathrm{~A} & 35.3 & 49.9 & 34.3-96.7 & 50 \\ 62 \mathrm{~A} & 34.8 & >46.4 & 24.6-72.3 & 47 \\ 83 \mathrm{~B} & 62.1 & 121 & 62.8-202 & 120 \\ \text { Drum } 72= & \text { Drums } 84+72 \mathrm{~A} & & & \\ 72 & 215.3 & 147-829 & 200-202 & 202 \\ 84 & 94.8 & 140-756 & 99.8-295 & 140 \\ 72 \mathrm{~A} & 145.6 & 189-898 & 137-447 & 189\end{array}$


IABLE 7. (Continued)

Safeguards

Drum

\& Security (g Pu) Gamma

Drum $83=$ Drum 83A

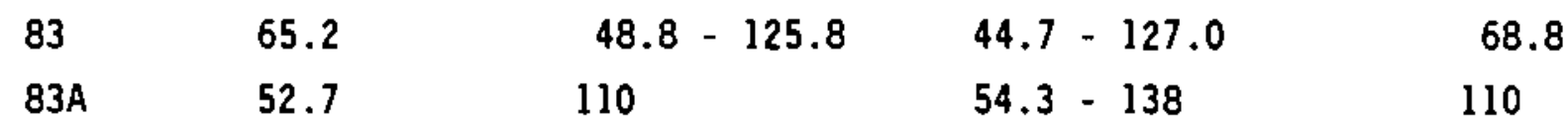

Drum $85=$ Drum 88

$\begin{array}{lllllll}85 & 273 & 229 & -993 & 267 & -709 & 267 \\ 88 & 272 & 162 & -370 & 253 & -649 & 253\end{array}$

Drum $86=$ Drum 89

$\begin{array}{ccccc}86 & 34.2 & 42.9-90.3 & 37.9-107.7 & 42.9 \\ 89 & 39.6 & 29.4-111 & 36.2-96.5 & 59 \\ \text { Drum } 86 \mathrm{~B} & = & \text { Drums } 86 \mathrm{~A}+89+83 \mathrm{~A} & & \\ 86 \mathrm{~B} & 95.9 & 187 & 93.5-251 & 190 \\ 86 \mathrm{~A} & 3.3 & 5.37 & 5.20 & 5.3 \\ 89 & 39.6 & 29.4-111 & 36.2-96.5 & 59 \\ 83 \mathrm{~A} & 52.7 & 110 & 54.3-138 & 110 \\ \text { Drum } 87 \mathrm{~A} & =\text { Drums } 87+62+2 \mathrm{~A} & & \\ 87 \mathrm{~A} & 109.1 & >159 & 103-336 & 160 \\ 87 & <0.09 & 1.08-1.59 & 1.04-3.72 & 1 \\ 62 & 53.1 & 112-240 & 59.6-59.9 & 112 \\ 2 \mathrm{~A} & 28.0 & 48.6 & 31.7-76.8 & 49\end{array}$

Drum $88=$ Drums $55 A+89 A$

$\begin{array}{llrrrrr}88 & 272 & 162 & -370 & 253 & -649 & 253 \\ 55 A & 115 & 104 & -534 & 135 & -381 & 220 \\ 89 A & 111 & >160 & & 105 & -293 & 160\end{array}$

Drum $90 \mathrm{~A}=$ Drums $55+92$

$\begin{array}{lrcrlr}90 A & 104.3 & 206 & 97.8-310 & 210 \\ 55 & 72.9 & 51.3-144 & 81.6-82.1 & 81.9 \\ 92 & 9.0 & 8.57 & 5.73- & 16.4 & 8.6\end{array}$


TABLE 8. Material Balance Ratios*

\begin{tabular}{|c|c|c|c|c|c|c|c|c|}
\hline \multirow[b]{2}{*}{ Drum } & \multirow{2}{*}{$\begin{array}{l}\text { Safeguards } \\
\& \quad \text { Security }\end{array}$} & \multicolumn{7}{|c|}{ Barrel Assayer } \\
\hline & & 1 & 2 & 3 & 4 & 5 & 6 & 7 \\
\hline 70 & 1.41 & 7.70 & 2.23 & 4.34 & 1.31 & 2.28 & 3.02 & 2.05 \\
\hline 72 & 1.12 & 2.24 & 2.03 & 2.00 & 1.18 & 2.43 & 3.67 & 1.63 \\
\hline 67 & & 1.42 & 1.22 & 1.36 & 1.51 & 1.78 & 4.04 & 1.64 \\
\hline 86 & 1.16 & 1.46 & 1.05 & 1.23 & 1.05 & 1.10 & 1.12 & 1.38 \\
\hline 83 & 1.24 & 2.25 & 1.26 & 1.14 & 1.21 & 1.12 & 1.09 & 1.60 \\
\hline 2 & 1.22 & 1.35 & 1.51 & 2.28 & 1.02 & 1.04 & 1.06 & 1.33 \\
\hline 85 & 1.00 & 1.41 & 2.30 & 2.68 & 1.06 & 1.08 & 1.09 & 1.06 \\
\hline 88 & 1.20 & 1.63 & 1.80 & 1.88 & 1.05 & 1.01 & 1.04 & 1.50 \\
\hline 868 & 1.00 & 1.29 & 1.01 & 1.21 & 1.02 & 1.03 & 1.05 & 1.09 \\
\hline $87 \mathrm{~A}$ & 1.35 & 1.02 & 1.42 & 1.83 & 1.12 & 1.89 & 2.39 & 1.01 \\
\hline $90 \mathrm{~A}$ & 1.23 & 3.37 & 1.92 & 2.34 & 1.12 & 2.19 & 3.15 & 2.29 \\
\hline . & 1.19 & 2.29 & 1.61 & 1.94 & 1.15 & 1.63 & 2.07 & 1.51 \\
\hline std. & 0.13 & 1.94 & 0.47 & 0.94 & 0.15 & 0.69 & 1.21 & 0.40 \\
\hline
\end{tabular}

* Ratio required to bring replicate analyses of parts vs. Whole into agreement

1. Tow value determined by gamma-ray analys is

2. median value determined by gamma-ray analysis

3. high value determined by gamma-ray analys is

4. low value determined by neutron analysis

5. median value determined by neutron analysis

6. high value determined by neutron analysis

7. "best" value. 
TABLE 9. Ratio Comparison of Analytical Data on Critical-Mass-Laboratory Waste Drums

\begin{tabular}{|c|c|c|c|c|c|}
\hline Drum & $\begin{array}{l}\text { Safeguards } \\
\& \text { Security } \\
\text { Gamma(g Pu) }\end{array}$ & $\begin{array}{l}\text { Barrell } \\
\text { Assayer } \\
\text { "Best" } \\
(\mathrm{g} . \mathrm{Pu})\end{array}$ & $\begin{array}{l}\text { Ratio } \\
\text { Best/S\&S }\end{array}$ & $\begin{array}{l}\text { Barre11 } \\
\text { Assayer } \\
\text { Neutron } \\
(g \mathrm{Pu})\end{array}$ & $\begin{array}{c}\text { Ratio } \\
\text { Neutron/S\&S }\end{array}$ \\
\hline \multirow[t]{2}{*}{$\begin{array}{l}2 \\
2 A \\
13 \\
17 A \\
52 \\
55 \\
55 A \\
62 \\
62 A \\
67 \\
70 \\
70 A \\
72 \\
72 A \\
79 \\
81 \\
82 \\
83 \\
83 A \\
83 B \\
84 \\
85 \\
86 \\
86 A \\
86 B \\
87 A \\
88 \\
89 \\
89 A \\
90 \\
90 A \\
91 \\
92 \\
93\end{array}$} & $\begin{array}{r}34.2 \\
28.0 \\
44.7 \\
204.0 \\
61.0 \\
72.9 \\
115.0 \\
53.1 \\
34.8 \\
127.3 \\
185.8 \\
35.3 \\
215.3 \\
145.6 \\
50.1 \\
49.4 \\
74.0 \\
65.2 \\
52.7 \\
62.1 \\
94.8 \\
273.0 \\
34.2 \\
3.3 \\
95.9 \\
109.1 \\
272.0 \\
39.6 \\
111.0 \\
2.6 \\
104.3 \\
3.6 \\
9.0 \\
14.9\end{array}$ & $\begin{array}{r}36.8 \\
49.0 \\
36.4 \\
72.0 \\
63.1 \\
81.9 \\
220.0 \\
112.0 \\
47.0 \\
254.0 \\
106.0 \\
50.0 \\
202.0 \\
189.0 \\
47.2 \\
30.2 \\
57.4 \\
68.8 \\
110.0 \\
120.0 \\
140.0 \\
267.0 \\
42.9 \\
5.3 \\
190.0 \\
160.0 \\
253.0 \\
59.0 \\
160.0 \\
1.3 \\
210.0 \\
1.9 \\
8.6 \\
15.0\end{array}$ & $\begin{array}{l}+1.08 \\
+1.75 \\
-1.23 \\
-2.83 \\
+1.03 \\
+1.12 \\
+1.91 \\
+2.11 \\
+1.35 \\
+2.00 \\
-1.75 \\
+1.42 \\
-1.07 \\
+1.30 \\
-1.06 \\
-1.64 \\
+1.29 \\
+1.06 \\
+2.09 \\
+1.93 \\
+1.48 \\
-1.02 \\
+1.25 \\
+1.61 \\
+1.98 \\
+1.47 \\
-1.08 \\
+1.49 \\
+1.44 \\
-2.00 \\
+2.01 \\
-1.89 \\
-1.05 \\
+1.01\end{array}$ & $\begin{array}{r}31.1 \\
31.7 \\
34.2 \\
52.2 \\
57.5 \\
81.6 \\
135.0 \\
59.6 \\
24.6 \\
252.0 \\
93.0 \\
34.3 \\
200.0 \\
137.0 \\
47.1 \\
25.2 \\
33.6 \\
44.7 \\
44.3 \\
54\end{array}$ & $\begin{array}{l}-1.10 \\
+1.13 \\
-1.31 \\
-3.91 \\
-1.06 \\
+1.12 \\
+1.17 \\
+1.12 \\
-1.41 \\
+1.98 \\
-2.00 \\
-1.03 \\
-1.08 \\
-1.06 \\
-1.06 \\
-1.96 \\
-2.20 \\
-1.46 \\
+1.03 \\
+1.01 \\
+1.05 \\
-1.02 \\
+1.11 \\
+1.58 \\
-1.03 \\
-1.06 \\
-1.08 \\
-1.09 \\
-1.06 \\
-1.07 \\
-6.83 \\
-1.57 \\
-1.04\end{array}$ \\
\hline & 2877.8 & 3466.8 & +1.20 & 2610.5 & -1.10 \\
\hline
\end{tabular}




\section{CONCLUSION}

Several approaches have been presented to validate the operation of the PNL Barrel Assayer on both TRU and non-TRU waste drums.

One test describes the re-analysis of resin-filled calibration barrels containing known quantities of ${ }^{60} \mathrm{Co},{ }^{137} \mathrm{Cs}$, and ${ }^{134} \mathrm{Cs}$. The observed activity levels matched the expected levels, while an analysis of the data generated from a thorium nitrate secondary standard verified that the detector was within calibration for the period from February 1989 through December 1990.

Data were also presented describing the assay of 23 non-TRU waste drums at two separate commercial nuclear power plants. Comparison of grab samples from $0 i 1$ and ion-exchange-resin filled drums validate the operation of the Barrel Assayer on non-TRU waste drums.

The Barrel Assayer was also employed to analyze several barrels containing TRU wastes. The results are compared to results obtained with an alternative technology and validate the operation of the PNL.Barrel Assayer on TRU waste drums. 



\section{REFERENCES}

Hensley, W. K., E. A. Lepel, M. E. Yuly, and K. H. Abel. 1988. J. Radioanal. Nucl. Chem. Art. .124, 481.

Gunnink, R., and J. B. Niday. 1972. Computerized Quantitative Analysis by Gamma-Ray Spectrometry, Vol 1-4. UCRL-51061, Lawrence Livermore Nationa1 Laboratory, Livermore, Cal ifornia.

Gunnink, R., and W. Ruhter. 1980. GRPANL: A Program for Fitting Complex Peak Groupings for Gamma- and X-Ray Energies and Intensities. UCRL-52917, Lawrence Livermore National Laboratory, Livermore, California.

Cline, J. E., and J. R. Noyce. 1985. Assay of Long-Lived Radionuclides in Low-Level Wastes from Power. Science Applications International Corp., Rockville, Maryland.

Robertson, D. E., R. L. Brodzinski, and J. D. Forsythe. 1989. Radionuclide Characterization of Potentia) Below-Requlatory-Concern (BRC) Waste Streams From Commercial Nuclear Power Stations. PNWD-1326, Battelle, Pacific Northwest Laboratories, Richland, Washington.

Robertson, D. E., et al. 1989. 8elow Regulatory Concern Dwners Group Radionuclide Characterization of Potential BRC Waste Types from Nuclear Power Stations. EPRI NP-5677s, Research Project B101-15, Electric Power Research Institute, 3412 Hillview Avenue, Palo Alto, California. 


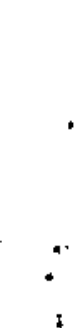




\section{DISTRIBUTION}

No. of

Copies

12 DOE/Office of Scientific and Technical Information

\section{ONSITE}

5 DOE Richland Operations office

C. Adair, A4-35

J. E. Adams, $A 6-55$

R. P. Denise, A4-35

D. N. Fujiyoshi, A5-52

D. K. Jones, A5-90

8 Westinghouse Hanford Company

H. R. Benze1, N3-13

P. R. Booten, $\times 3-68$

J. J. Jernberg, $\times 3-68$

R. A. Larson, $\times 3-68$

C. D. Lucas, $\times 0-35$

M. L. Martin, $\times 0-35$

R. J. Pyzel, $\times 0-42$

C. L. Volkman, $x 1-80$

\section{Pacific Northwest Laboratory}

R. J. Arthur, P8-08 (30)

R. L. Brodzinski, P8-07

D. L. Haggard, K3-70

R. R. LaBarge, $P 7-72$

W. W. Lajty, K2-50

L. G. Morgan, P8-07

R. C. Schrotke, Jr., P8-33

J. W. Smith, P7-72

Publishing Coordination

Technical Report Files (5) 
: 